\title{
Chemical Effect of Dry and Wet Cleaning of the Ru Protective Layer of the Extreme Ultraviolet (EUV) Lithography Reflector
}

\author{
Leonid Belau', Jeong Y. Park ${ }^{2}$, Ted Liang ${ }^{3}$, Hyungtak Seo ${ }^{1}$, and Gabor A. Somorjai ${ }^{1,2, *}$ \\ ${ }^{1}$ Department of Chemistry, University of California, Berkeley, California 94720 \\ ${ }^{2}$ Chemical Sciences Division, Lawrence Berkeley National Laboratory, Berkeley, CA \\ 94720 \\ ${ }^{3}$ Components Research, Technology and Manufacturing Group, Intel Corporation, Santa \\ Clara, CA 95054
}

\begin{abstract}
We report the chemical influence of cleaning of the $\mathrm{Ru}$ capping layer on the extreme ultraviolet (EUV) reflector surface. The cleaning of EUV reflector to remove the contamination particles has two requirements; to prevent corrosion and etching of the reflector surface and to maintain the reflectivity functionality of the reflector after the corrosive cleaning processes. Two main approaches for EUV reflector cleaning: wet chemical treatments (sulfuric acid and hydrogen peroxide mixture (SPM), ozonated water, and ozonated hydrogen peroxide) and dry cleaning (oxygen plasma and UV/ozone treatment) were tested. The change of surface morphology and roughness were characterized using scanning electron microscopy (SEM) and atomic force microscopy (AFM), while the surface etching and change of oxidation states were probed with X-ray photoelectron spectroscopy (XPS). Significant surface oxidation of the Ru capping layer was observed after oxygen plasma and UV/ozone treatment, while the oxidation is unnoticeable after SPM treatment. Based on these surface studies, we found that SPM treatment exhibits the minimal corrosive interactions with $\mathrm{Ru}$ capping layer. We address
\end{abstract}


the molecular mechanism of corrosive gas and liquid-phase chemical interaction with the surface of Ru capping layer on the EUV reflector.

* Corresponding author, e-mail address: somorjai@ berkeley.edu

Material names: Ruthenium, Ruthenium oxide, sulfuric acid, hydrogen peroxide, and ozonated water 


\section{Introduction}

A leading next-generation lithographic tool is based on the utilization of extreme ultraviolet (EUV) radiation. The most common wavelength of the light source for EUVrelated applications is the Si L-shell X-ray photoemission edge at $13.5 \mathrm{~nm}$. So far, the best EUV reflector design known for lithographic purposes at $13.5 \mathrm{~nm}$ is based on the stacking multilayer concept. The highest reflectivity rate of almost $70 \%$ has been achieved by using 40 pairs of Si/Mo multilayers (ML) with a period of $6.8 \mathrm{~nm}$ that is the half of the EUV wavelength (13.5 nm).(1-5) Schematic representation of the EUV reflector scheme and the TEM image are shown in Figure 1. Such reflector is used for the reflectors in the exposure tool optics and ML blanks for making EUV reflector. In this paper, the focus is on the investigation of chemical cleaning of ML blanks that is the model system of EUV reflector unless it is stated otherwise. Due to the high oxidation reactivity of the top Si layer, a capping protective layer is required. At the moment, the best capping material for the EUV reflector is a thin $2-3 \mathrm{~nm} \mathrm{Ru}$ layer covering the top $\mathrm{Si}$ layer of the reflective coating. It is chosen because of its optical properties (high transmission coefficient at $13.5 \mathrm{~nm}$ ) and high chemical resistance for many corrosive environments, including acids and bases $(6 ; 7)$.

One of the problems is the contamination of the ML blank surface after EUV exposure and during its handling (8-13). Because light with wavelength of $13.5 \mathrm{~nm}$ is easily absorbed by almost all absorbed gas residues, the built-up carbon based contamination on the reflector surface decreases the reflectivity of the reflectors. Moreover, the chemical etching of the photoresist in various phases of the process leads 
to reflector surface contamination by small particles that cannot be removed using conventional cleaning technology. These particles create a serious problem for a desired lithographic fabrication of $22 \mathrm{~nm}$ half-pitch node devices.

Taking into account that the lithographic reliability depends both on the quality and the nature of the surface, the cleaning processes that remove contamination and restore the photomask pattern are one of the most important aspects in the semiconductor industry. Due to EUV radiation induced surface contamination and particles falling on the surface during mask handling and usage, the cleaning of the mask surface is one of the most frequent tasks among all processes involved in EUV lithography. Thus, it is necessary to optimize the cleaning procedure to be able to minimize the reflector surface damage while maintaining high cleaning efficiency (14). A number of cleaning methods including plasma, UV/ozone, cleaning with reducing agent like hydrogen (15-18) have been suggested and tested. Molecular-level understanding of the surface interaction between the Ru capping layer and the cleaning chemical agent is challenging and the aim of our study.

In this work, we report the chemical and morphological change of the Ru surface of the EUV reflector with surface sensitive techniques (19) including XPS, and AFM. These techniques are applied to understand the nature and efficiency of the EUV reflector cleaning with various cleaning processes including oxygen plasma and UV/ozone, sulfuric and hydrogen peroxide (SPM), ozonated water, and ozonated hydrogen peroxide treatment. This work can help to predict the efficiency and challenges of various cleaning techniques applied to clean the surface of the EUV reflector. 


\section{Experimental details}

A model system of EUV mask is fabricated using magnetron sputter deposition of 40 alternative layers of $\mathrm{Si}$ and $\mathrm{Mo}$, with a standard period of $7 \mathrm{~nm}$, followed by the deposition of Ru layer on 4" Si wafers with two Ru thicknesses: $3 \mathrm{~nm}$ and $6 \mathrm{~nm}$. $3 \mathrm{~nm}$ is the normal thickness for standard ML blanks. The thicker $6 \mathrm{~nm} \mathrm{Ru}$ cap layer is used to allow easy measurements of surface changes in some of the studies in this paper. Chemical surface composition is studied using both high and low resolution XPS. High resolution XPS analysis is performed using a NOVA XPS (Kratos) with an X-ray monochromator and an $\mathrm{Al} \mathrm{K}_{\alpha}$ anode (operated at $1486.6 \mathrm{eV}$ ). Low resolution XPS is Physical Electronics: PHI 5400 ESCA/XPS system equipped with an Al anode X-ray source $(1486.6 \mathrm{eV})$.

AFM was employed to obtain a topographical image of the surface in air and estimate the surface roughness. Surface morphology analysis is performed using a Molecular Imaging AFM (RHK Technology) operated in the contact mode using a silicon nitride tip. SEM images of AFM tips revealed the tip radius of $30-40 \mathrm{~nm}$. Because the contact AFM experiment was carried out at the low load $(<5 \mathrm{nN})$, the change of tip radius was ignorable, as confirmed with SEM images taken after the AFM experiment (20). SEM analysis is performed with a Variable Pressure Field Emission SEM Model S4300SE/N (Hitachi).

The SPM treatment is performed in the Pyrex container. $\mathrm{H}_{2} \mathrm{SO}_{4}(98 \%)$ and $\mathrm{H}_{2} \mathrm{O}_{2}$ (30\%) are mixed together at a standard ratio of 5:1. During mixing, the temperature is elevated to almost $100^{\circ} \mathrm{C}$. Small samples (typically 1/4" dia.) are introduced into the fresh 
mixture for $15 \mathrm{~min}$. After that, the samples are rinsed in DI water and flashed out with dry air. For ozonated water treatment, the sample is mounted on a Pyrex dish filled with DI water. The water level is about $4 \mathrm{~mm}$ above the sample surface. Ozone is generated using the UVO-CLEANER apparatus for a certain time. After the treatment, the sample is flashed with dry air. For the hydrogen peroxidetreatment the same procedure is applied. However, instead of DI water, the sample was covered with an $\mathrm{H}_{2} \mathrm{O}_{2}$ mixture (30 $\%)$.

For oxygen plasma cleaner, Harrick plasma, $\mathrm{PDC}-32 \mathrm{G}$ at $18 \mathrm{~W}$ and typical $\mathrm{O}_{2}$ pressure of 300 mTorr was used. EUV reflector samples are mounted on the flat glass holder and introduced into the Pyrex chamber of the plasma generator. The chamber was pumped down and a low pressure of oxygen at 300 mTorr leaks into the chamber during treatment. For UV/ozone treatment, UVO-CLEANER, model 42 (Jelight Company, Inc. ) with the output power of $28 \mathrm{~mW} / \mathrm{cm}^{2}$ at $253.7 \mathrm{~nm}$. Small samples of EUV reflector are mounted on the Pyrex sample holder and introduced into the UVO-CLEANER apparatus. Ozone is generated using a $253.7 \mathrm{~nm}$ low pressure $\mathrm{Hg}$ lamp $10 \mathrm{~mm}$ above the sample. Natural oxygen from the atmosphere is used to generate the ozone.

\section{Results and discussions}

\section{III.A. SPM treatment}


XPS chemical analysis of the $6 \mathrm{~nm}$ Ru capping layer on the ML blank after 15 min of SPM $\left(\mathrm{H}_{2} \mathrm{SO}_{4}: \mathrm{H}_{2} \mathrm{O}_{2}=5: 1\right)$ treatment was carried out. The high resolution XPS spectra of $\mathrm{Ru} 3 \mathrm{~d}$ and $\mathrm{O} 1 \mathrm{~s}$ regions of the $6 \mathrm{~nm} \mathrm{Ru}$ capping layer after SPM treatment obtained at $90^{\circ}$ takeoff angle are shown in Fig. 2(a) and 2(b), respectively. Figure 2(c) and 2(d) are XPS spectra of $\mathrm{Ru} 3 \mathrm{~d}$ and $\mathrm{O} 1 \mathrm{~s}$ regions obtained at $10^{\circ}$ takeoff angle. There are two major components that contribute to the shape of the photoelectron peak in the $\mathrm{Ru} 3 \mathrm{~d}_{5 / 2}$ region. The peak at the lower binding energy $(279.7 \mathrm{eV})$ is attributed to the metallic $\mathrm{Ru}\left(\mathrm{Ru}^{0}\right)$ and the peak at the higher binding energy $(280.4 \mathrm{eV})$ is due to the most stable oxide, $\mathrm{RuO}_{2}\left(\mathrm{Ru}^{4+}\right)$. Two components in XPS peaks of the $\mathrm{O}$ 1s are noticeable: the peak at the lower binding energy $(529.5 \mathrm{eV})$ is associated with oxygen atoms from $\mathrm{RuO}_{2}$ $\left(\mathrm{O}^{2-}\right)$ and the peak at the higher binding energy $(531.3 \mathrm{eV})$ corresponds to weakly bounded oxygen atoms associated with chemisorbed and dissolved (subsurface) oxygen in the $\mathrm{Ru}$ lattice and on the surface (21).

The only discrepancy between SPM treated and untreated samples is in the $\mathrm{Ru}$ $3 \mathrm{~d}_{3 / 2}$ region, which overlaps with $\mathrm{C} 1 \mathrm{~s}$ photoelectrons. Thus, these spectra differences are attributed to lower carbon coverage on untreated sample. This fact suggest that although SPM treatment is causing the Ru capping layer oxidation it is very minor change that is barely seen after $15 \mathrm{~min}$ of treatment. Similar spectra comparison at the grazing photoelectron takeoff angle $\left(\theta=10^{\circ}\right)$ is conveying the same conclusion: no significant oxidation of the $\mathrm{Ru}$ capping layer. Higher photoelectron intensity around $285 \mathrm{eV}$ is related to carbon contamination on the treated sample

The cleaning capability of this type of SPM treatment is tested using the same EUV reflector type with a thick (up to $100 \mu \mathrm{m}$ ) film of mineral oil. XPS analysis after cleaning this sample in SPM solution shows that the oil is successfully removed during 
15 min of treatment. Thus, laboratory based cleaning of EUV reflectors with SPM solution is comparable with the industrial process. The ML blank morphology before and after SPM treatment does not show any significant changes. AFM images obtained of the same sample show very minor changes of the surface roughness. Before and after the treatment, the roughness is $\sigma=1.8 \pm 0.5 \AA$. It appears that SPM treatment does not significantly affect the ruthenium capping layer and is effective for removal of a very thick layer of organic contamination. Surface oxidation of the $\mathrm{Ru}$ capping layer is very minor. The amount of $\mathrm{RuO}_{2}$ and subsurface oxygen after SPM cleaning is very similar to the virgin sample. Ru capping layer surface roughness undergoes very small changes.

\section{III.B. Ozonated water and ozonated hydrogen peroxide}

The ML blank treated with ozonated water and ozonated solution of hydrogen peroxide shows changes in the oxidation states of the $\mathrm{Ru} 3 \mathrm{~d}$ photoelectron peak. XPS analysis of the $6 \mathrm{~nm} \mathrm{Ru}$ layer is performed using the low resolution XPS apparatus at a $45^{\circ}$ photoelectron takeoff angle. XPS spectra comparison of virgin sample and after cleaning with ozonated water and hydrogen peroxide solution in the $\mathrm{Ru} 3 \mathrm{~d}$ region are shown in Figure 3.

Comparison of the normalized spectra of the $\mathrm{Ru} 3 \mathrm{~d}$ energy level in Figure 3 reveals that ozonated water and hydrogen peroxide treatments of the $\mathrm{Ru}$ capping layer leads to slight broadening of the $\mathrm{Ru} 3 \mathrm{~d}_{5 / 2}$ photoelectron peak on the higher binding energy side. The surface oxidation of $\mathrm{Ru}$ layer is not significant after cleaning in ozonated water, which is similar to SPM cleaning. It is not reliable to convey a similar 
type of information from the $\mathrm{Ru} 3 \mathrm{~d}_{3 / 2}$ peak because of the unknown contribution of the $\mathrm{C}$ 1s photoelectron peak. XPS spectra of samples after ozonated water (Fig. 4a), hydrogen peroxide solution (Fig. 4b) and untreated sample (Fig. 4c) are shown in Figure 4, emphasizing the contribution of free-O and $\mathrm{O}^{2-}$ photoelectron peaks. XPS spectra comparison in the $\mathrm{O} 1$ s region, Figure 4, exhibits the formation of a large amount of free$\mathrm{O}$ atoms (or $\mathrm{OH}$ ) after ozonated hydrogen peroxide treatment (blue line). In contrast, the relative intensity of $\mathrm{O}^{2-}$ to free-O is higher in the $\mathrm{Ru}$ capping layer after it is treated with ozonated water, Figure 4(a). The relative abundance of oxygen to ruthenium is higher in the $\mathrm{Ru}$ capping layer after both cleaning methods. The $I(R u 3 d) / I(O 1 s)$ ratio shows that it drops from $4.0 \pm 0.2$, for the virgin sample, down to $0.6 \pm 0.2$ and $1.6 \pm 0.2$ for ozonated $\mathrm{H}_{2} \mathrm{O}_{2}$ and ozonated water, respectively. This is quantitative evidence that the concentration of the oxygen increases significantly after these treatments.

The fact that the XPS spectrum after ozonated hydrogen peroxide treatment, Figure 4(b), has a high abundance of free-oxygen (blue curve) is crucial to understanding the mechanism of surface treatment in the oxygen rich environment. During ozonated hydrogen peroxide treatment, the Reflector surface is exposed to a high concentration of $\mathrm{OH}$ radicals. This is possible because $\mathrm{H}_{2} \mathrm{O}_{2}$ is absorbing $\mathrm{UV}$ radiation, leading to $\mathrm{H}_{2} \mathrm{O}_{2}$ photofragmentation to give two reactive hydroxyl radicals: $\mathrm{H}_{2} \mathrm{O}_{2}+h v \rightarrow 2 \mathrm{HO}$. Exposing the $\mathrm{Ru}$ capping layer to an exceedingly strong oxidizing environment does not significantly increase the amount of $\mathrm{RuO}_{2}$ in it. Thus, we can conclude that $\mathrm{Ru}$ surface treatment using an ozonated solution of hydrogen peroxide primarily causes free-oxygen dissolution in the bulk and less Ru oxidation. It is interesting that the relative amount of $\mathrm{RuO}_{2}$ is rather similar after sample treatment with ozonated water and hydrogen peroxide. 
This is revealed when comparing the relative ratio of the $\mathrm{Ru} 3 \mathrm{~d}$ peak with the deconvoluted photoelectron peak in the $\mathrm{O} 1 \mathrm{~s}$ region associated with $\mathrm{O}^{2-}$.

The surface roughness samples after ozonated water and hydrogen peroxide wet treatments are studied using scanning AFM imaging. In contrast to SPM treatment, the effect of the ozonated water and ozonated hydrogen peroxide on the $\mathrm{Ru}$ capping layer roughness is noticeable. The surface roughness increased from $1.8 \pm 0.5 \AA$ to $4.5 \pm 0.7 \AA$ and $5.0 \pm 0.7 \AA$, for virgin sample, ozonated water and ozonated hydrogen peroxide, respectively. This could indicate an etching of the Ru capping layer on the ML blank. However, in order to predict the difference in the etching rate for these two solutions, more experimental evidences are required. In summary, ML blank treated with ozonated water and hydrogen peroxide leads to oxidation of the Ru capping layer and formation of $\mathrm{RuO}_{2}$. The relative amount of $\mathrm{RuO}_{2}$ created in the $\mathrm{Ru}$ capping layer is similar in samples treated with ozonated water and with ozonated hydrogen peroxide. Chemical treatment with ozonated hydrogen peroxide increases tremendously the amount of subsurface oxygen species due to dissolution of $\mathrm{OH}$ radicals in the Ru capping layer. Both methods cause surface etching of the $\mathrm{Ru}$ capping layer, as revealed when comparing the increase of surface roughness.

\section{III.C. Oxygen plasma and UV/ozone treatment}

The chemical effect of two dry cleaning methods, oxygen plasma and UV/ozone oxidation were tested. Oxygen plasma is widely used for resist strip in semiconductor wafer processing. Additionally, among the many cleaning methods used in the 
semiconductor industry, oxygen plasma is known as an effective method for carbonaceous contamination removal without adding new particles on the surface $(9 ; 11$; 15; 22) The UV/ ozone oxidation has been used for decades as a means of cleaning slightly soiled surfaces for a variety of applications, for example, removal of organic capping layers on metal nanocatalysts. (23-25) Ultraviolet radiation can also be used for polymer surface modification with applications in photolithography, microfluidics, and bioengineering. The method typically uses ultraviolet light that includes the wavelengths of 185 and $257 \mathrm{~nm}$, where the former generates ozone upon interacting with molecular oxygen. The UV/ozone oxidation process involves the simultaneous action of ozone and ultraviolet light, which are responsible for the oxidation of the carbon containing compounds into carbon dioxide and water.

It has been known that these cleaning methods etch $\mathrm{Ru}$ metals (26), which can cause to roughen the surface and remove $\mathrm{Ru}$ layers. Removal of the $\mathrm{Ru}$ capping layer from the ML blank reduces the durability of the EUV mask. It is, therefore, important to understand the mechanism of the corrosive gas phase-surface interactions to improve existing cleaning processes and Ru-based capping layer of the EUV mask. Oxidation kinetics of the Ru capping layer of the ML blank was studied using a low resolution XPS apparatus. Two samples with $3 \mathrm{~nm}$ and $6 \mathrm{~nm}$ Ru capping layers are systematically treated with oxygen plasma cleaner at the same conditions, but different exposure times. XPS spectra at $45^{\circ}$ photoelectron takeoff angle are shown in Figure 5.

XPS spectra comparison in the $\mathrm{O}$ 1s energy region, Figure 5a, shows severe oxidation of the Ru capping layer on the ML blank. The peak centered at $529.5 \mathrm{eV}$, associated with $\mathrm{RuO}_{2}$, rises significantly after the first $20 \mathrm{~s}$ of $\mathrm{O}_{2}$ plasma treatment. However, the intensity ratio of the $\mathrm{O}^{2-}$ and free-O peaks approaches equilibrium after $20 \mathrm{~s}$ 
of exposure. The same conclusion is derived after the Ru $3 \mathrm{~d}_{5 / 2}$ XPS peak is analyzed (as shown in Figure 5(b): the ratio between $\mathrm{Ru}(0)$ and $\mathrm{Ru}(\mathrm{IV})$ peaks do not change significantly after the original increase, or after $20 \mathrm{~s}$.

The most plausible explanation for this effect is formation of volatile $\mathrm{RuO}_{4} \cdot \mathrm{RuO}_{2}$ is further oxidized to $\mathrm{RuO}_{4}$ due to intense $\mathrm{Ru}$ capping layer bombardment with very reactive oxygen atoms and cations (18). At standard conditions, $\mathrm{RuO}_{4}$ is very volatile and pumped out. Interestingly, this is the main volatile compound found in the gas phase during $\mathrm{O}_{2}$ plasma treatment. (26) Thus, etching of the $\mathrm{Ru}$ capping layer on ML blank is taking place through $\mathrm{RuO}_{4}$. Oxygen dissolution into the $\mathrm{Ru}$ capping layer is significant during $\mathrm{O}_{2}$ plasma treatment, in addition to $\mathrm{Ru}$ atom diffusion to the surface and formation of volatile $\mathrm{RuO}_{4}$. The concentration ratio changes of $\mathrm{Ru}$ and $\mathrm{O}$ are studied using low resolution XPS analysis. Due to overlap of the C 1 s photoelectron peak with $\mathrm{Ru} 3 \mathrm{~d}_{3 / 2}$, only $\mathrm{Ru} 3 \mathrm{~d}_{5 / 2}$ is used. The ratio $I\left(R u 3 d_{5 / 2}\right) / I(O 1 s)$ changes as function of $\mathrm{O}_{2}$ plasma exposure are shown in Figure 6. According to Figure 3, in both reflectors (with $3 \mathrm{~nm}$ and $6 \mathrm{~nm} \mathrm{Ru}$ capping layer), relative oxygen concentration increases after the first $20 \mathrm{~s}$ treatment. After the first $20 \mathrm{~s}$ exposure, change in the ratio $I\left(R u 3 d_{5 / 2}\right) / I(O 1 s)$ is not significant. This quantitatively proves that the system reaches steady state after $20 \mathrm{~s}$ of $\mathrm{O}_{2}$ plasma exposure.

AFM analysis of the $\mathrm{Ru}$ capping layer after different $\mathrm{O}_{2}$ plasma exposure times shows that the surface morphology undergoes serious changes. The roughness increases from the original $2.2 \pm 0.8 \AA$ to almost $5 \pm 0.8 \AA$. However, in contrast to XPS data, no steady state is observed for the surface roughness. Figure 7a shows the summary of the roughness analysis of the $3 \mathrm{~nm}$ Ru capping layer on ML blank obtained with $400 \mathrm{~nm} \mathrm{x}$ 
$400 \mathrm{~nm}$ contact mode AFM images. Figure 7b and 7c show AFM images of untreated Ru capping layer and $\mathrm{Ru}$ capping layer after 60 minutes of oxygen plasma. The RMS roughness of untreated and treated (60 minutes of oxygen plasma) are $0.2 \mathrm{~nm}$ and $0.5 \mathrm{~nm}$, respectively.

$\mathrm{O}_{2}$ plasma treatment of the $\mathrm{Ru}$ surface continuously increases the reflector surface roughness. This is due to the etching of the $\mathrm{Ru}$ layer. The most important test for the feasibility of using $\mathrm{O}_{2}$ plasma treatment of the $\mathrm{Ru}$ capping layer on ML blank is the reflectivity difference at $13.5 \mathrm{~nm}$ wavelength. Reflectivity measurements performed at different $\mathrm{O}_{2}$ plasma exposures for two reflectors with $3 \mathrm{~nm}$ and $6 \mathrm{~nm} \mathrm{Ru}$ capping layers are shown in Figure 8. The reference level for the industrial grade reflectivity of ML blank with $2.4 \mathrm{~nm} \mathrm{Ru}$ capping layer is shown as the red line. The reflectivity of ML blank with $3 \mathrm{~nm} \mathrm{Ru}$ capping is higher than that of $6 \mathrm{~nm}$ one because the $\mathrm{Ru}$ film is not completely transparent at this photon energy. The comparison of the two types of reflector does not show any significant changes in their reflectivity properties from the virgin level, even after long exposure to oxygen plasma. The etching rate of 0.15 $\mathrm{nm} /$ minute of the Ru capping layer was determined by comparing the high resolution TEM images before and after oxygen plasma treatment (18). The change in thickness of $\mathrm{Ru}$ capping layer after oxygen plasma was estimated with TEM measurement. Because the reflectivity measurement presented in Figure 8 was carried out with the exposure time ranging 0-90 second, the change in thickness of $\mathrm{Ru}$ capping layer is only $0.22 \mathrm{~nm}$. Therefore the influence of thickness change can be ignored in the reflectivity measurement. Also, the EUV transmission of $1 \mathrm{~nm}$ thick $\mathrm{RuO}_{2}$ film is $96.8 \%$, slightly lower than that of $\mathrm{Ru}$ (the same thickness) that is $98.6 \%$ (27), which shows that the change in reflectivity due to oxidation is not significant. Therefore, we can conclude that 
surface morphology changes, obtained using AFM, do not affect the reflectivity properties of ML blank (18).

Chemical analysis of the Ru capping layer after UV/ozone treatment on the EUV reflectors is studied using low and high resolution XPS equipment. Deconvolution analysis of XPS spectra in the $\mathrm{Ru} 3 \mathrm{~d}$ region and $\mathrm{O} 1 \mathrm{~s}$, shows that $\mathrm{Ru}^{4+}$ is the only oxidized state of $\mathrm{Ru}$ in the capping layer. Figure 9 shows the plot of the ratio of photoelectron $\mathrm{Ru} 3 \mathrm{~d}$ peak and the $\mathrm{O} 1 \mathrm{~s}(I(R u 3 d) / I(O 1 s)$ as a function of irradiation time obtained with the deconvolution of the $\mathrm{Ru} 3 \mathrm{~d}$ peak. The $\mathrm{Ru}$ capping layer oxidation is detected under UV irradiation of the ML blank at ambient pressure. This result is similar to those reported for oxygen plasma treatment. Plasma cleaning involves ion bombardment with low energy ions that usually does depend on the configuration of the reactor. Apparently, UV/ozone cleaning introduce the same level of damage with oxygen plasma, implying that the chemical processes are dominating for both cleaning methods, UV/ozone and oxygen plasma treatments.

\section{Conclusion}

We carried out studies showing changes in chemical and physical properties of the $\mathrm{Ru}$ capping layer after dry cleaning (oxygen plasma and UV/ozone treatment) and wet chemical treatments (SPM, ozonated water, and ozonated hydrogen peroxide) using XPS, AFM, TEM, and reflectivity measurements. Based on experimental results, the most efficient and the less disruptive method for the EUVL reflector cleaning in the industrial environment would be the SPM solution: lowest roughness change and Ru 
oxidation. The dry cleaning methods tested at this stage damage the surface of the ML blank and cause its lifetime reduction. After dry cleaning (oxygen plasma and UV/ozone cleaning), chemical analysis of the ML blank shows an increase in the subsurface oxygen concentration, Ru oxidation, and surface roughness. XPS spectra at various photoelectron takeoff angles suggest that the ML blank surface was covered with chemisorbed oxygen after oxygen plasma and UV treatment. The effect of the ozonated water and ozonated hydrogen peroxide on the $\mathrm{Ru}$ capping layer roughness is noticeable, in contrast to SPM treatment.

\section{Acknowledgments}

The authors acknowledge the contribution of Peter A. Coon and Gregory Perkins (Formerly Intel Corp.) for their help with high resolution XPS analysis; Erik Gullikson (CXRO, LBNL) for his help with reflectivity measurements. This work is funded by Intel Corp., and supported by the Director, Office of Science, Office of Basic Energy Sciences of the U.S. Department of Energy under Contract No. DE-AC02-05CH11231, 


\section{References}

[1] S. Bajt, J.B. Alameda, T.W. Barbee, W.M. Clift, J.A. Folta, B. Kaufmann, E.A. Spiller, Optical Engineering 41 (2002) 1797-1804.

[2] S. Bajt, et al., Journal of Microlithography Microfabrication and Microsystems 5 (2006).

[3] T. Liang, et al., Journal of Vacuum Science \& Technology B 25 (2007) 20982103.

[4] B.Q. Wua, A. Kumar, Journal of Vacuum Science \& Technology B 25 (2007) 1743-1761.

[5] M.F. Bal, M. Singh, J.J.M. Braat, Journal of Microlithography Microfabrication and Microsystems 3 (2004) 537-544.

[6] H. Over, Y.B. He, A. Farkas, G. Mellau, C. Korte, M. Knapp, M. Chandhok, M. Fang, Journal of Vacuum Science \& Technology B 25 (2007) 1123-1138.

[7] T.E. Madey, N.S. Faradzhev, B.V. Yakshinskiy, N.V. Edwards, Applied Surface Science 253 (2006) 1691-1708.

[8] K. Hamamoto, Y. Tanaka, T. Watanabe, N. Sakaya, M. Hosoya, T. Shoki, H. Hada, N. Hishinuma, H. Sugahara, H. Kinoshita, Journal of Vacuum Science \& Technology B 23 (2005) 247-251.

[9] W. Kern, Handbook of Semiconductor Wafer Cleaning Technology - Science, Technology, and Applications, William Andrew Publishing/Noyes, 1993.

[10] S.H. Lee, Y.K. Hong, J.H. Song, J.G. Park, A.A. Busnaina, G.J. Zhang, F. Eschbach, A. Ramamoorthy, Japanese Journal of Applied Physics Part 1-Regular Papers Brief Communications \& Review Papers 44 (2005) 5479-5483.

[11] I. Nishiyama, H. Oizumi, K. Motai, A. Izumi, T. Ueno, H. Akiyama, A. Namiki, Journal of Vacuum Science \& Technology B 23 (2005) 3129-3131.

[12] S. Osborne, N. M., T. H., W. E., K. C., T. J., Proceeding of SPIE 5992 (2005) 59923G-1.

[13] J.H. Ryu, D.W. Lee, J.S. Ryu, S.P. Kim, O. Han, Proceeding of SPIE 6349 $63492 \mathrm{~V}$. 
[14] T. Liang, T. Shimomura, Z. Zhang and G. Vandentop, "Requirements and Unique Challenges in EUV Mask Cleaning Development" Sematech Surface Preparation and Cleaning Conference Proceeding, Austin Texas (2008). .

[15] Y. Iwasaki, A. Izumi, H. Tsurumaki, A. Namiki, H. Oizumi, I. Nishiyama, Applied Surface Science 253 (2007) 8699-8704.

[16] H. Oizumi, A. Izumi, K. Motai, I. Nishiyama, A. Namiki, Japanese Journal of Applied Physics Part 2-Letters \& Express Letters 46 (2007) L633-L635.

[17] Y.B. He, et al., Journal of Physical Chemistry C 111 (2007) 10988-10992.

[18] L. Belau, J.Y. Park, T. Liang, G.A. Somorjai, J. Vac. Sci. Technol. B 26 (2008) 2225.

[19] G.A. Somorjai, R.L. York, D. Butcher, J.Y. Park, Physical Chemistry Chemical Physics 9 (2007) 3500-3513.

[20] T.F. Zhang, J.Y. Park, W.Y. Huang, G.A. Somorjai, Applied Physics Letters 93 (2008) 3.

[21] J.Y. Shen, A. Adnot, S. Kaliaguine, Applied Surface Science 51 (1991) 47-60.

[22] M.H.L. Van der Velden, W.J.M. Brok, J. Van der Mullen, V. Banine, Journal of Applied Physics 100 (2006).

[23] J.R. Vig, J. Vac. Sci. Technol. A 3 (1985) 1027-1034.

[24] C. Aliaga, J.Y. Park, Y. Yamada, H.S. Lee, C.K. Tsung, P.D. Yang, G.A. Somorjai, Journal of Physical Chemistry C 113 (2009) 6150-6155.

[25] J.Y. Park, C. Aliaga, J.R. Renzas, H. Lee, G.A. Somorjai, Catalysis Letters 129 (2009) 1-6.

[26] C.C. Hsu, J.W. Coburn, D.B. Graves, Journal of Vacuum Science \& Technology A 24 (2006) 1-8.

[27] Calculated using the on-line resource at the website of Center for X-ray Optics in Lawrence Berkeley National Laboratory. http://henke.lbl.gov/optical_constants/filter2.html. See B.L. Henke, E.M. Gullikson, and J.C. Davis. X-ray interactions: photoabsorption, scattering, transmission, and reflection at $\mathrm{E}=50-30000 \mathrm{eV}, \mathrm{Z}=1-92$, Atomic Data and Nuclear Data Tables Vol. 54 (no.2), 181-342 (July 1993). 


\section{Figure captions}

Figure 1. TEM image of that ML blank that is composed of Ru layer covered on Si/Mo multilayers with a period of $6.8 \mathrm{~nm}$ that is the half of the EUV wavelength $(13.5 \mathrm{~nm})$.

Figure 2. Angular resolved XPS spectra of $\mathrm{Ru} 3 \mathrm{~d}$ and $\mathrm{O} 1 \mathrm{~s}$ regions of the $6 \mathrm{~nm} \mathrm{Ru}$ capping layer after SPM treatment. (a) and (b) obtained at $90^{\circ}$ takeoff angle, (c) and (d) obtained at $10^{\circ}$ takeoff angle.

Figure 3. (On-line color) XPS of $6 \mathrm{~nm} \mathrm{Ru}$ capping layer on the ML blank in $\mathrm{Ru} 3 \mathrm{~d}$ region after ozonated water (red dotted line), ozonated hydrogen peroxide (blue dotted line), and untreated samples (black solid line).

Figure 4. (On-line color) XPS of $6 \mathrm{~nm}$ Ru capping layer on the ML blank in the $\mathrm{O} 1 \mathrm{~s}$ region at $45^{\circ}$ takeoff angle measured (a) after ozonated water for $100 \mathrm{~min}$, (b) ozonated hydrogen peroxide for $100 \mathrm{~min}$, and (c) on untreated samples.

Figure 5. Low resolution XPS spectra in (a) O1s and (b) $\mathrm{Ru} 3 \mathrm{~d}_{5 / 2}$ regions of the $3 \mathrm{~nm} \mathrm{Ru}$ capping layer on the EUV reflector obtained at different exposures to oxygen plasma.

Figure 6. Plot of intensity ratio of $\mathrm{Ru} 3 \mathrm{~d}_{5 / 2}$ and $\mathrm{O} 1 \mathrm{~s}$ peak after $\mathrm{O}_{2}$ plasma treatment as a function of exposure time for the $3 \mathrm{~nm}$ and $6 \mathrm{~nm} \mathrm{Ru}$ capping layer on the ML blank.

Figure 7. (a) Plot of Surface roughness of $3 \mathrm{~nm} \mathrm{Ru}$ capping layer as a function of $\mathrm{O}_{2}$ plasma doses. AFM images (400 nm x $400 \mathrm{~nm}$ ) of (b) untreated Ru capping layer and (c) $\mathrm{Ru}$ capping layer after 60 minutes of oxygen plasma. The RMS roughness of untreated and treated (60 minutes of oxygen plasma) are $0.2 \mathrm{~nm}$ and $0.5 \mathrm{~nm}$, respectively.

Figure 8. The reflectivity at $13.5 \mathrm{~nm}$ measurement of the ML blank with $3 \mathrm{~nm}$ and $6 \mathrm{~nm}$ $\mathrm{Ru}$ capping layer as a function of $\mathrm{O}_{2}$ plasma doses.

Figure 9. The plot of the ratio of photoelectron peak intensities of $\mathrm{Ru} 3 \mathrm{~d}$ and $\mathrm{O} 1 \mathrm{~s}$ as a function of UV/ozone exposure on 3nm and $6 \mathrm{~nm}$ Ru capping layer of the ML blank. 


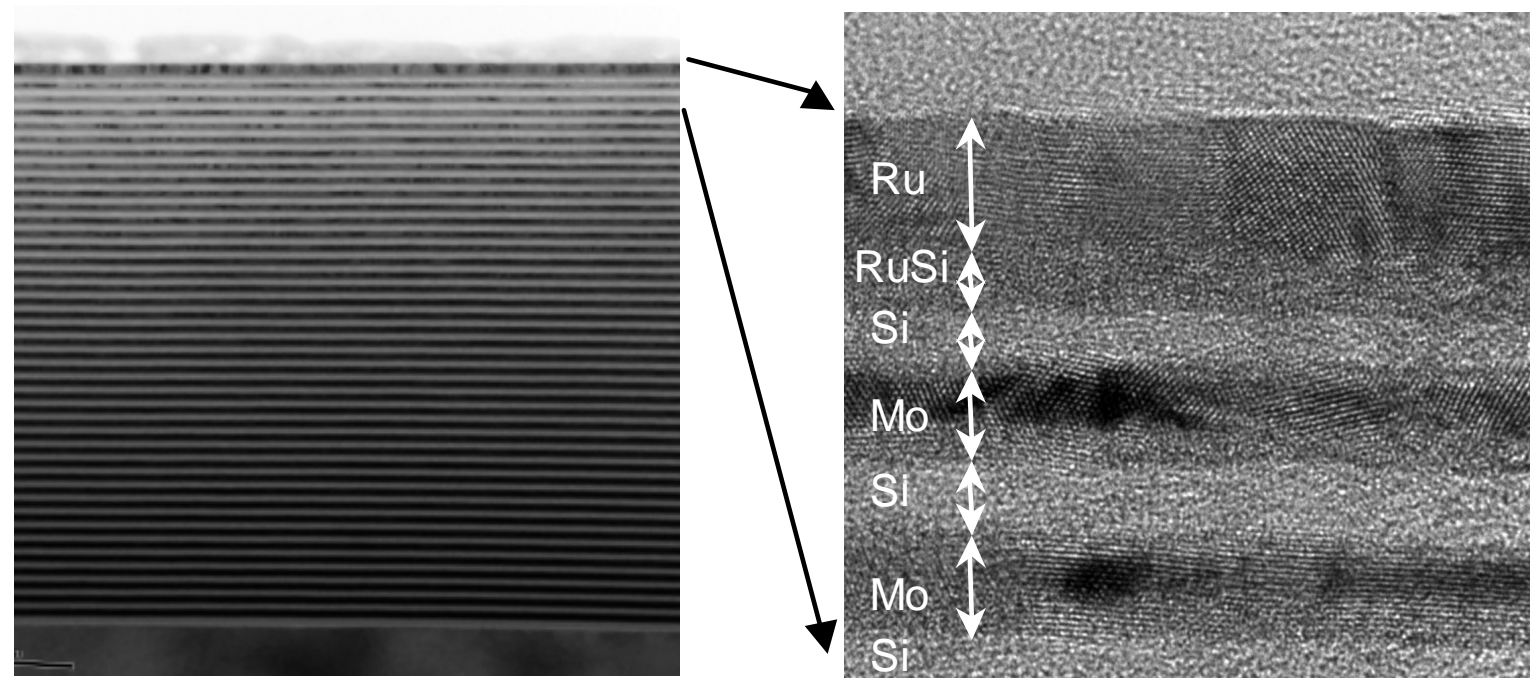

Figure 1. 


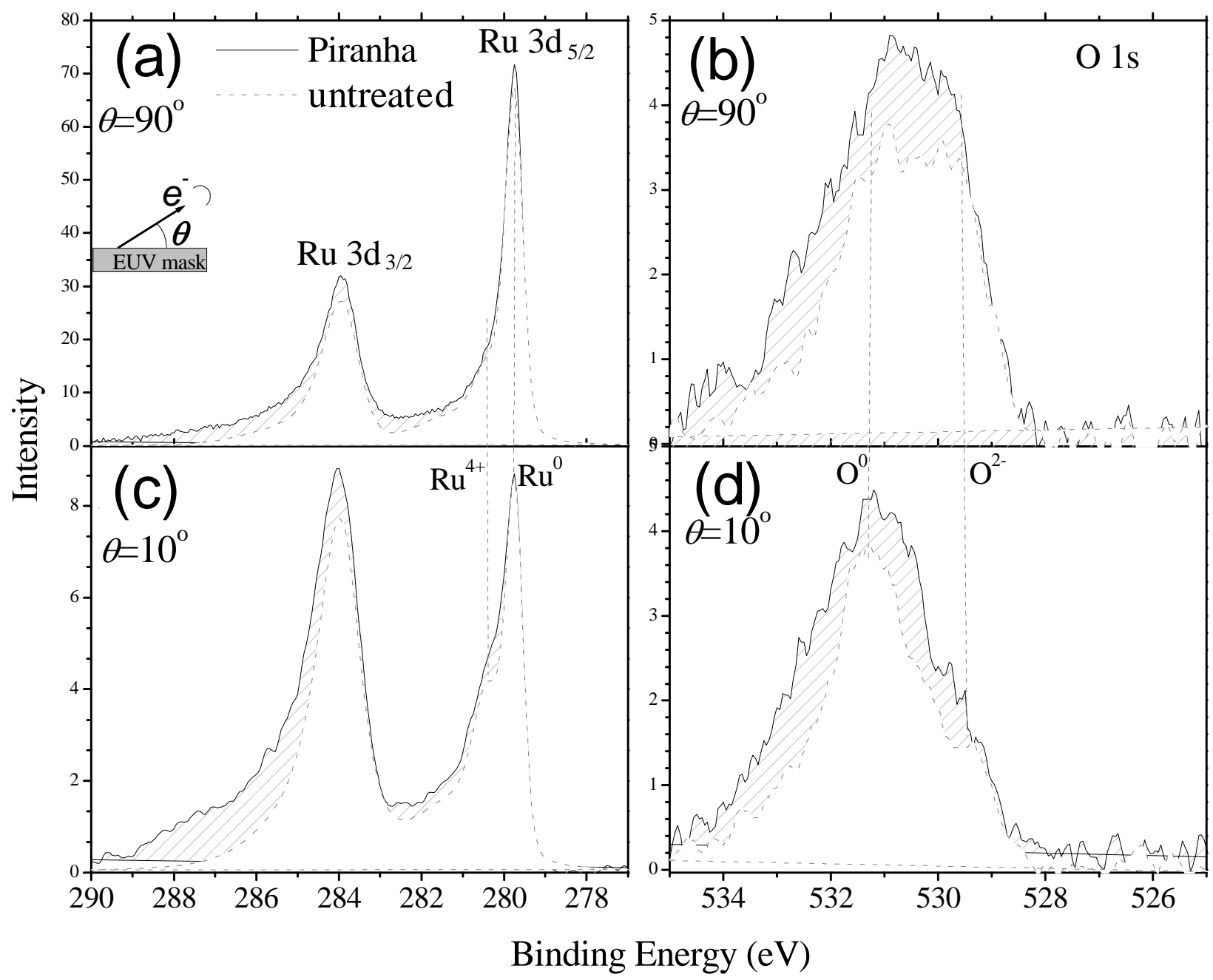

Figure 2. 


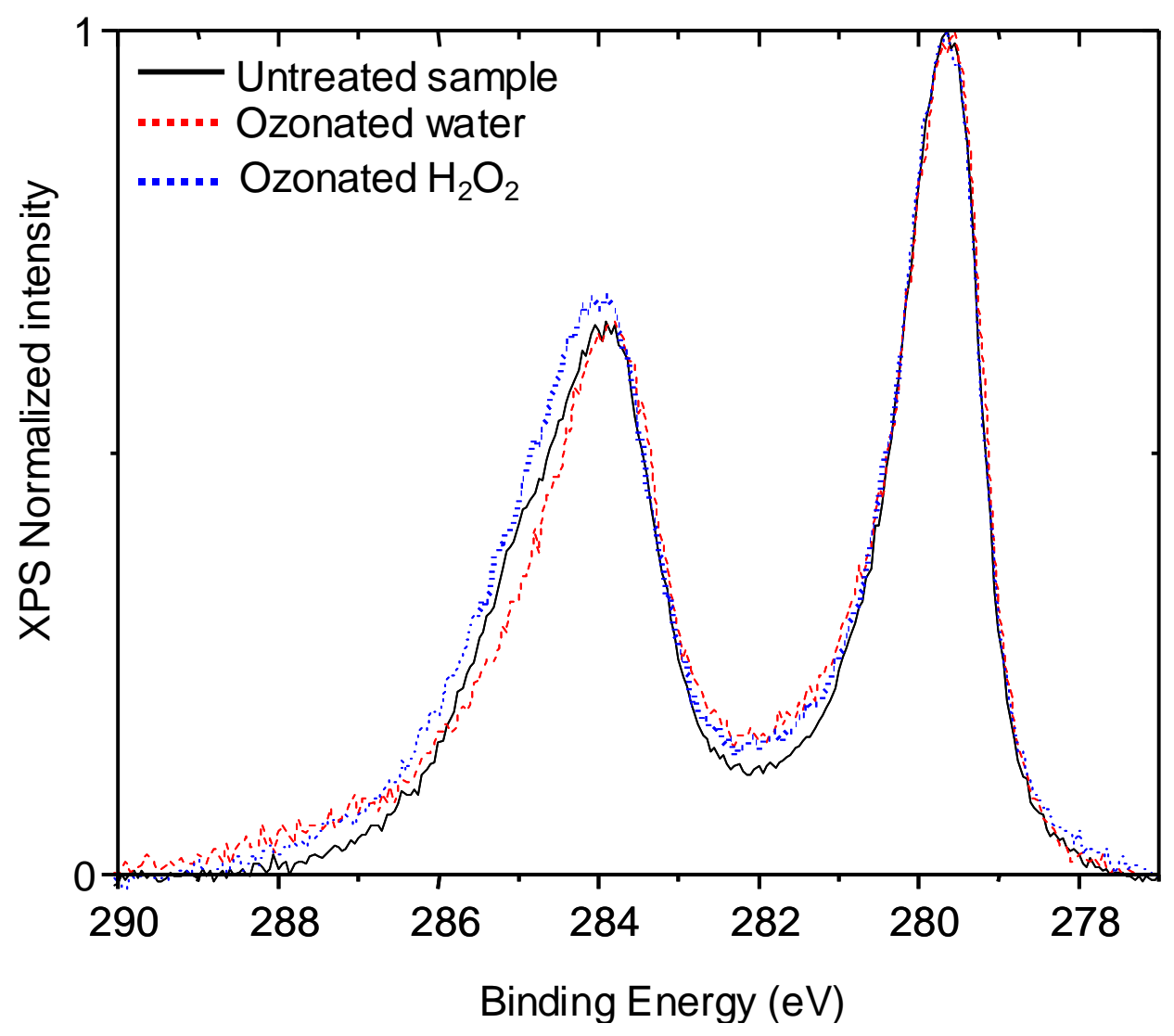

Figure 3. 


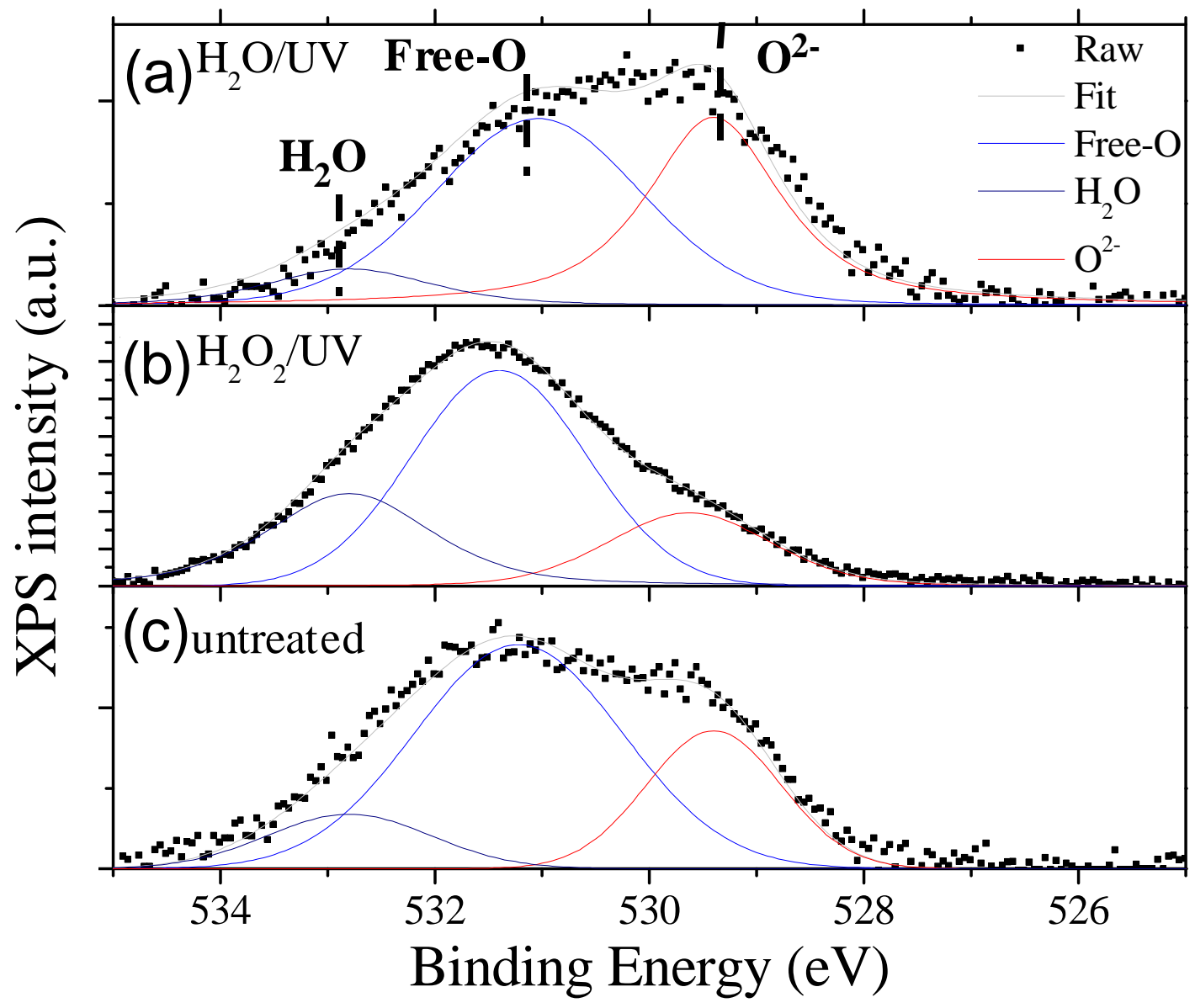

Figure 4. 


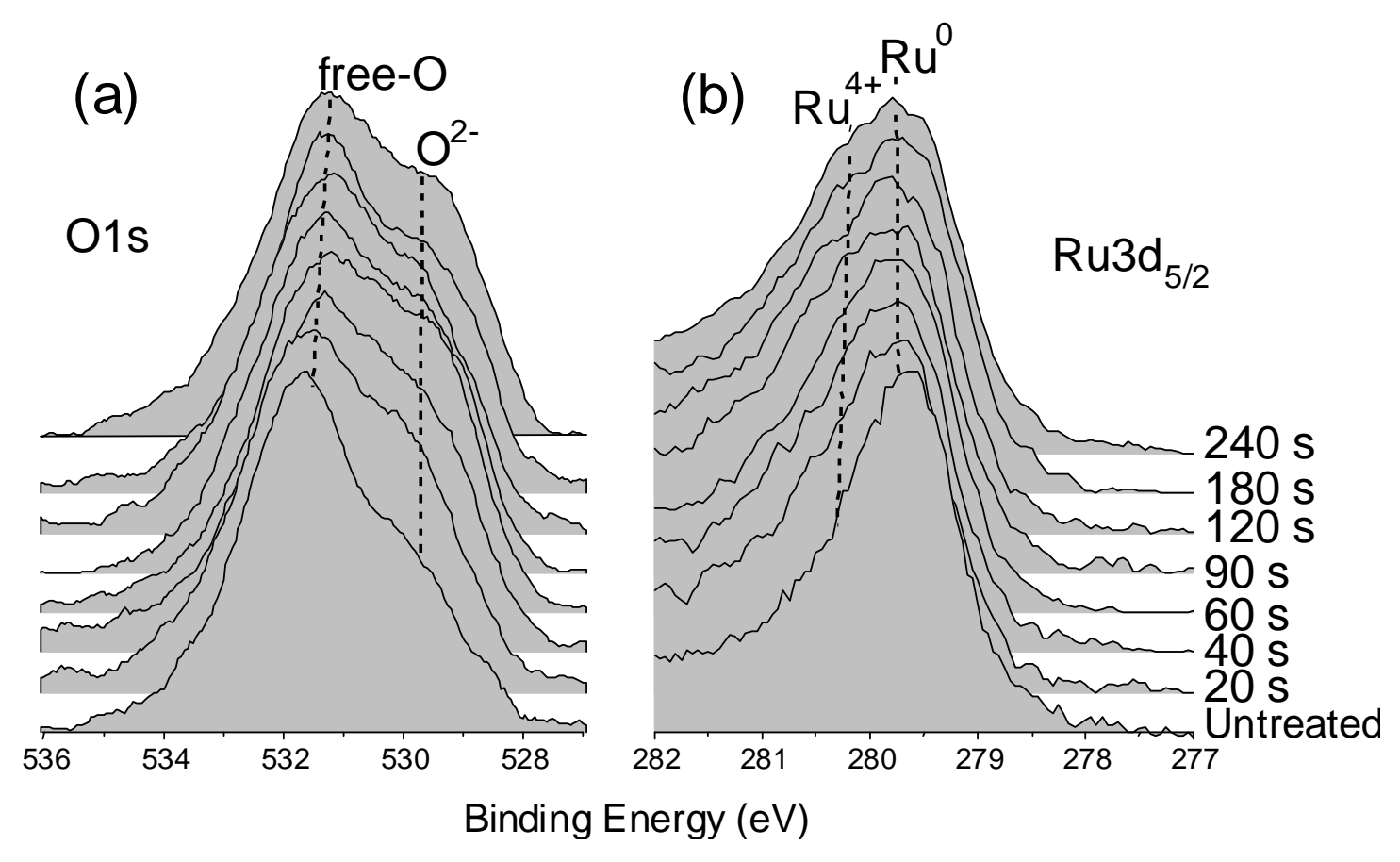

Figure 5. 


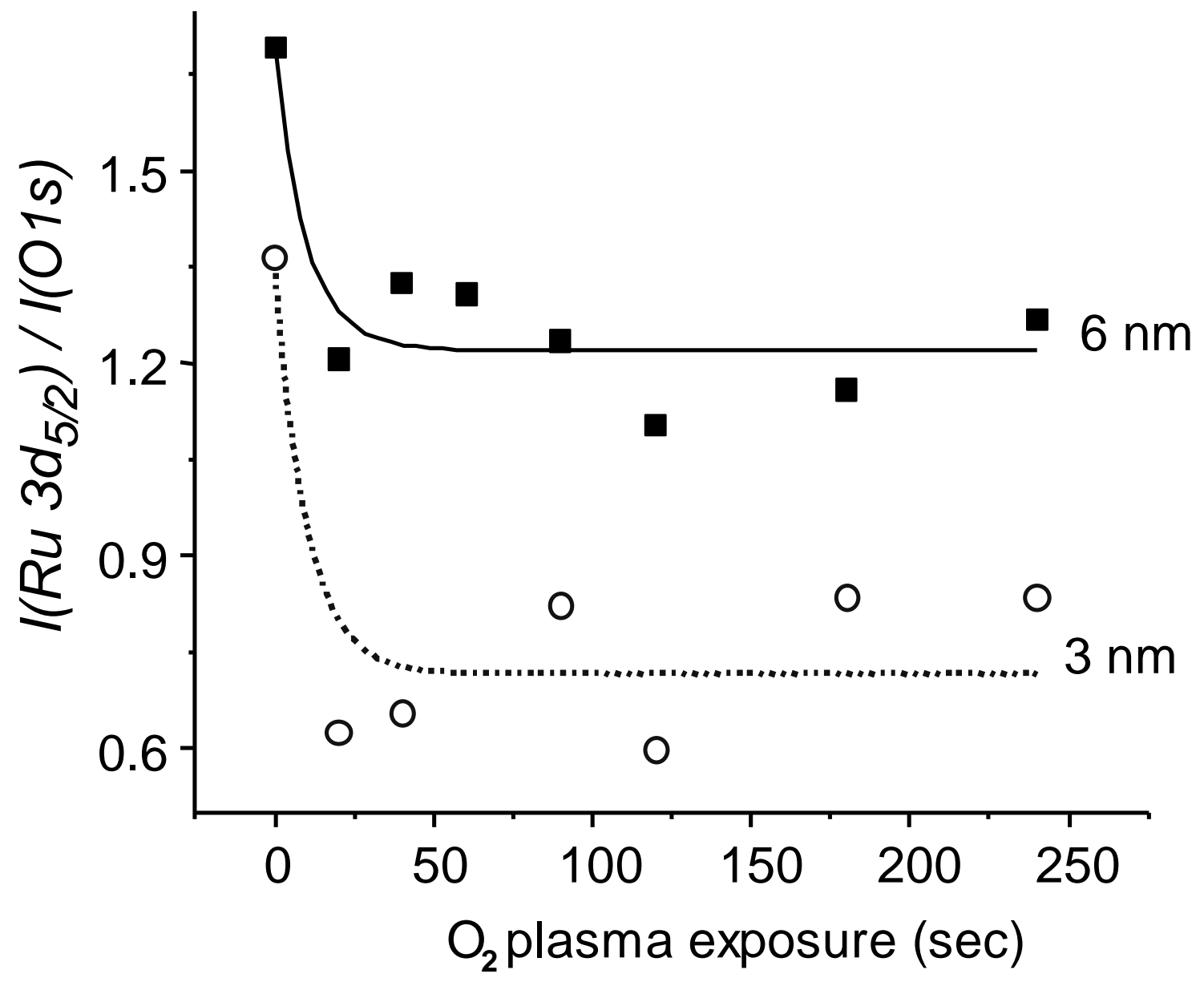

Figure 6. 

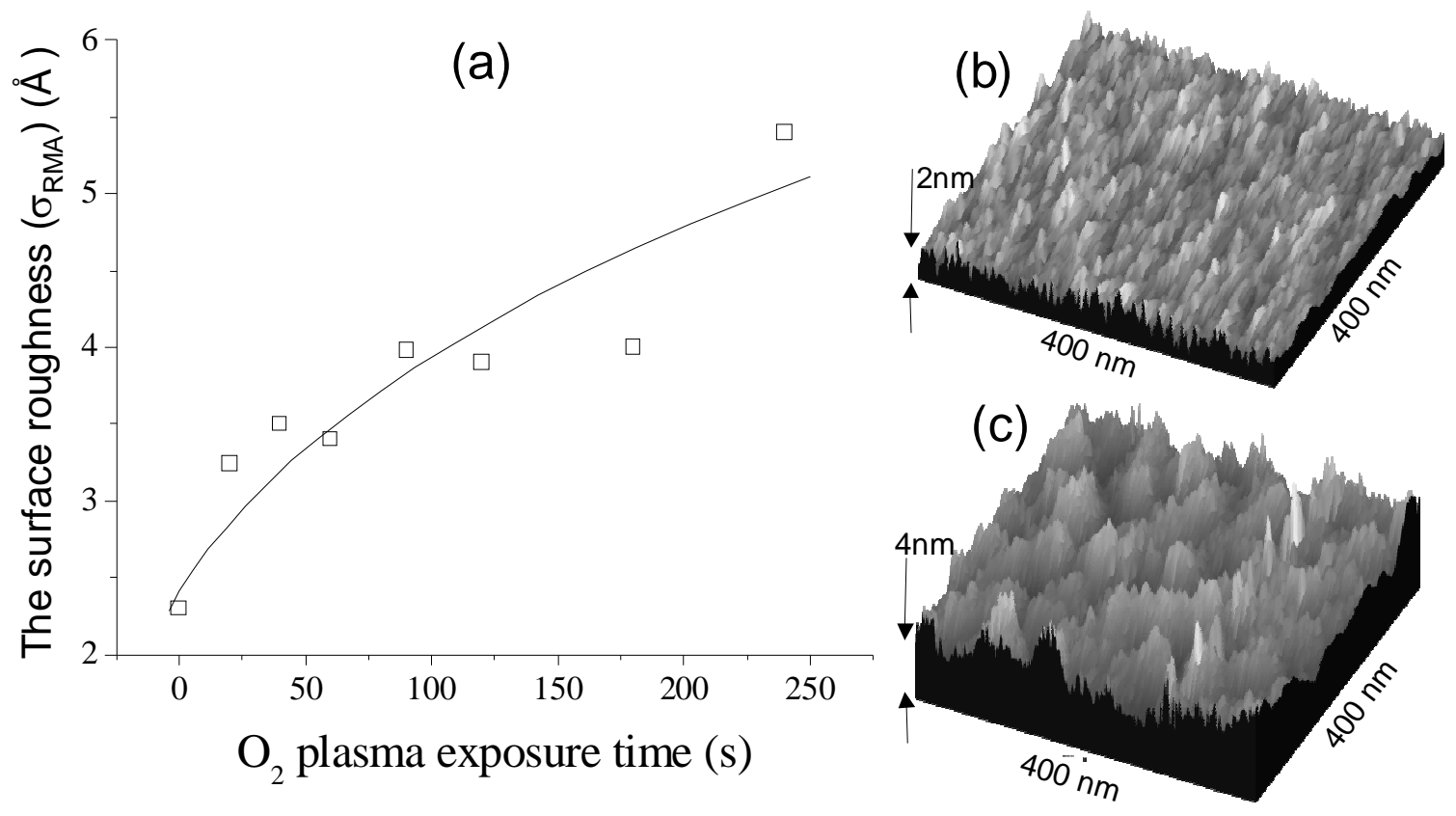

Figure 7. 


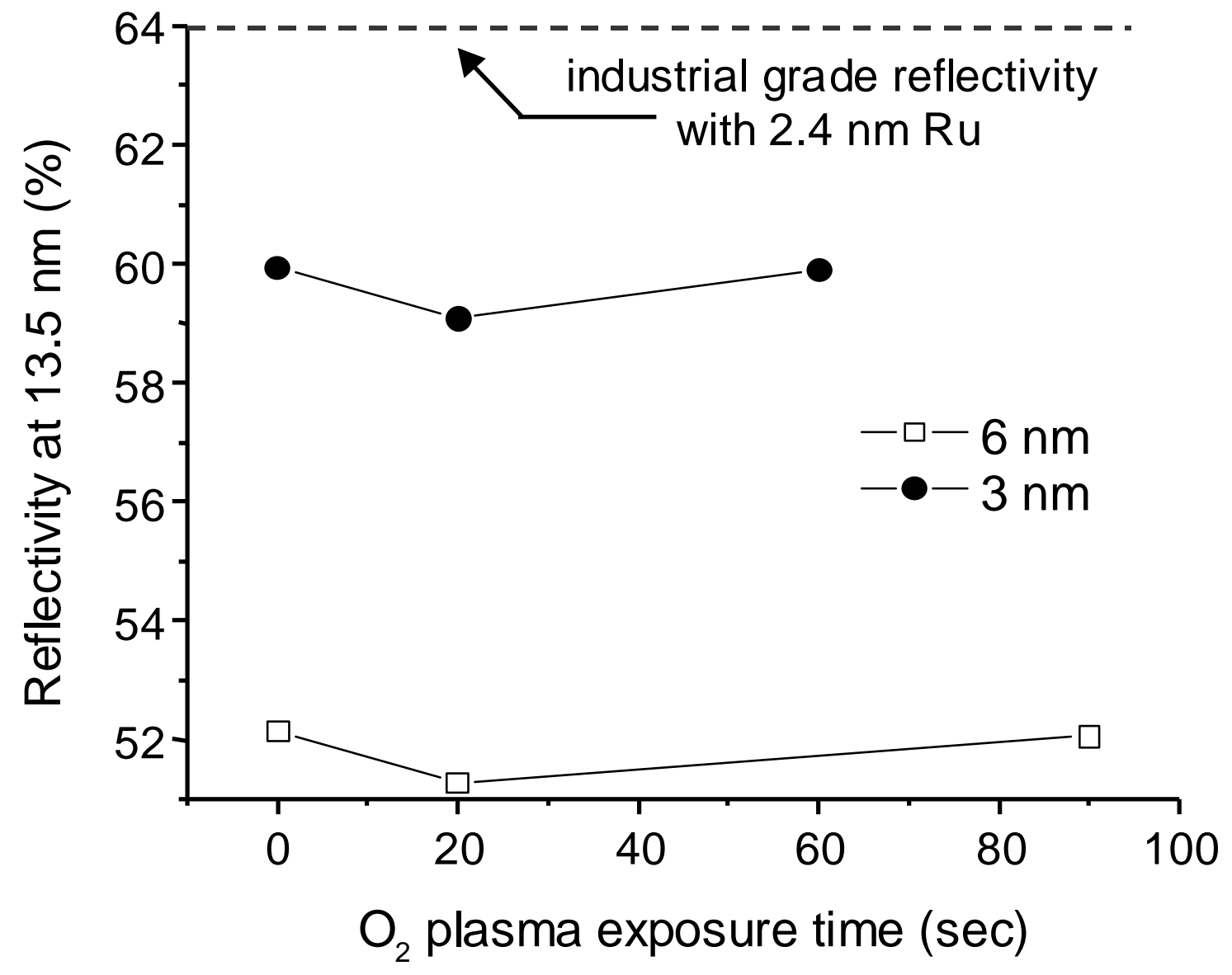

Figure 8. 


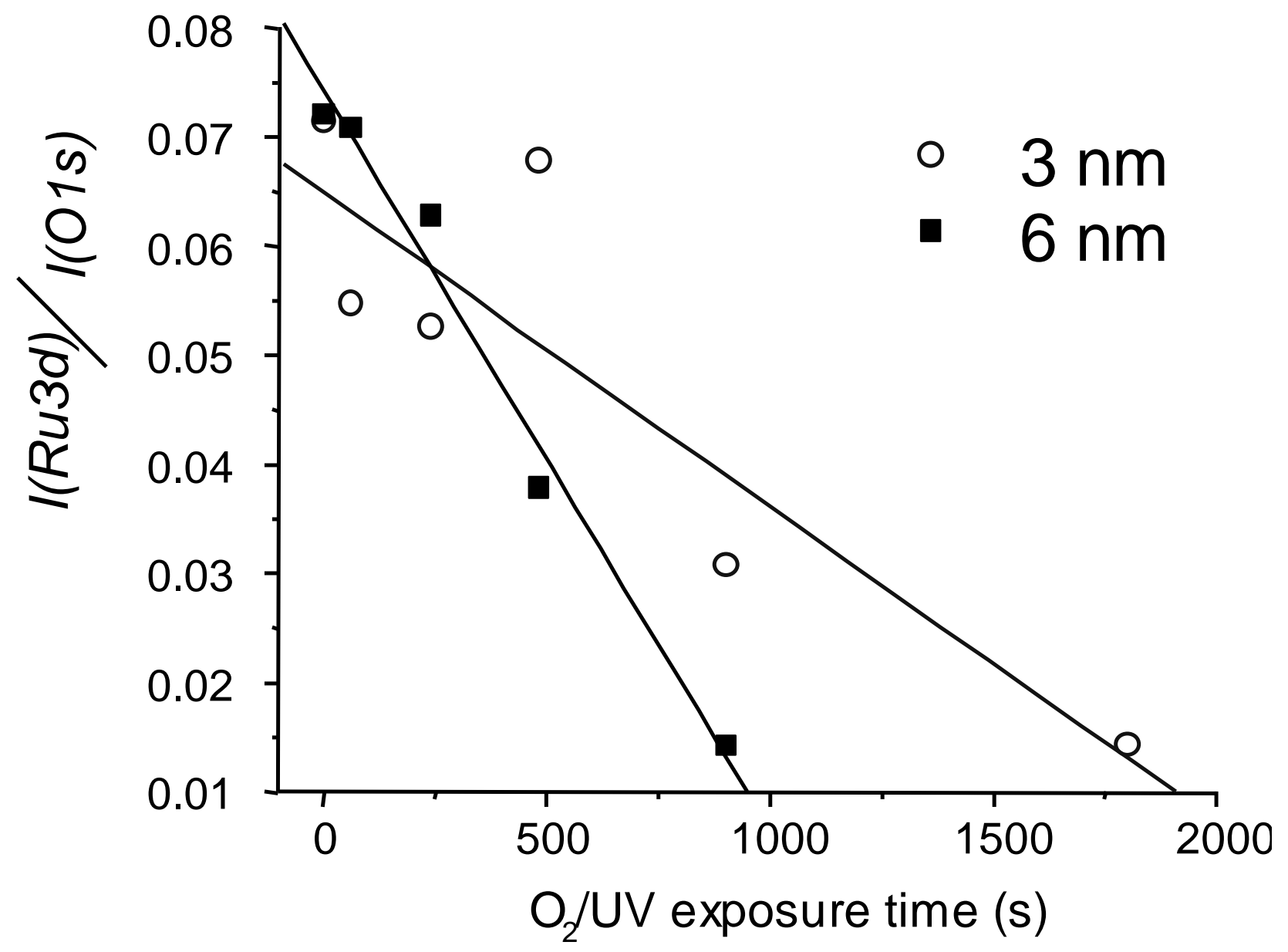

Figure 9. 